paratyphoid-A infection in India and in other endemic areas is not yet known and may well be much higher than that estimated for Bombay. There can be little doubt that the phage-typing method used as an epidemiological tool will prove to be an indispensable aid to the ultimate control of this infection.

$$
\text { D. D. Banker }
$$

Department of Pathology and Bacteriology, Seth G.S. Medical College, Parel, Bombay 12. Dec. 15.

'Craigle, J., and Felix, A., Lancet, i, 823 (1947). Felix, A., and Callow' B. R., Lancet, ii, 10 (1951). B. R., Lancet, ii, 10 (1951).
(1938).,

selix, A., Report to Int. Com. for Enteric Phage Typing, Fifth Int. Congress Microbiol., Rio de Janeiro, August 1950.

- Felix, A., Brit. Med. Bull., 7, 153 (1951). - Felix, A., Report to Int. Com. for Enteric Phage Typing,S ixth

- Felix, A., J. Hyg., 50, 540 (1952).

Dhayagude, R. G., and Banker, D. D., Ind. J. Med. Res., 39, 1 (1951).

\section{Nature of the Pigment of Aplysia depilans}

By heating an aqueous solution of the actual excretion of the Mediterranean sea-slug Aplysia depilans, the violet pigment is separated from its protein part. The colour of the aqueous solution varies conformably with the $p \mathrm{H}$, from blue $(p \mathrm{H} 1-2)$ to garnet red $(p \mathrm{H} \quad 8-12 \cdot 0)$.

The chloroform solutions of this pigment exhibit maxima at $6100,5350,4975$ and $3800 \mathrm{~A}$. (spectrum I), and they yield violet, red and green zones upon a column of powdered sugar. The violet pigment is absorbed in the top of the column, while the red is absorbed in the middle part, and the green pigment, travelling faster, at the end of the column.

Elution with chloroform-ethanol mixture $(2 ; 1)$ : the chromatographically separated violet pigment exhibits maxima at 5860, 5290, $4925 \mathrm{~A}$., and its zinc complex salt at $6280,5927,5440$ and 5040 A. (III). The red pigment shows maxima at 5910,5315 and $5007 \mathrm{~A}$. Its zinc complex salt shows maxima at 5950, 5500 and 5015 A. (II). The third greenish-blue

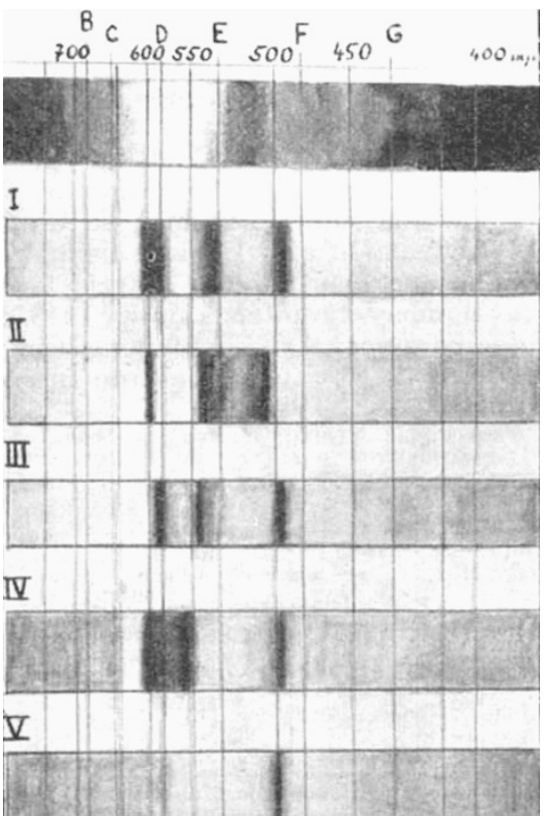

pigment shows no absorption maxima in the visible range, but an extinction of colour in the violet and red regions of the spectrum. Unfortunately, because of its very low concentration, we could not distinguish absorption bands.

The ethanolic solutions of all three pigments separated show intensive red-brownish fluorescence. The chloroform solutions of the actual pigment, as well as the solutions of the three pigments separated, become dark blue when treated with a stream of dry hydrogen chloride. This blue chloroform-soluble pigment exhibits maxima at 5950,5475 and $4927 \mathrm{~A}$. (IV), and gives with zinc acetate a reddish-brown fluorescence with maximum at 5982, 5495 and $5055 \mathrm{~A}$. and simultaneous extinction in the red and violet regions. After several "hours, the blue pigment becomes greenish, and its spectrum shows an intense extinction in the red to $5583 \mathrm{~A}$., with only a maximum at $4955 \mathrm{~A}$. (V); its zine complex salt exhibits maxima at 6255 and $4983 \mathrm{~A}$.

The Gmelin reaction of these compounds is negative or very atypical. This fact, in combination with the red fluorescence, suggests that they are porphyrin in nature'. They do not behave like bilichromes ${ }^{2}$.

Details of this work will be published in the Bulletin of the Academy of Sciences, Athens.

A. Christomanos

Sea Animals Biochemical Research Laboratory, St. George, Limni,

Euboea Island, Greece. Oct. 10.

${ }^{1}$ C.R. Soc. Biol., Paris, 92, 1030 (1953). Fox, "Animal Blochromes . Soc. Biol., Paris, 92, 1030 (1953). Fox, "Animal Blochromes 8 Lederer and Hutter, Trans. Mem. Soc. Chim. Biol., 1055 (1942).

\section{Peculiar Stratified Shape of Typhoon Waves}

WHm. M.V. Tancred of the Barber Line was riding out the typhoon of early October 1954 in Kobe Bay, we were able to observe a unique shape of typhoon wave which, so far as we know, has not been described. The vessel was hove-to with two anchors down facing the incoming gale $(133 \mathrm{~km} . / \mathrm{hr}$.) and the waves with crests up to 10 and $15 \mathrm{ft}$. were passing neatly along her side. From the rail we were struck by the peculiar appearance of the wave-slopes facing the wind.

On many of these there were a number of welldefined steps, carved so to say into the water just like the steps of a ladder, starting from the trough of the wave up to about half its height. Although the waves were moving quickly the steps remained steady, extending parallel to each other for one or two metres in length. There were at times as many as twenty of these nicely successive steps cut into the body of the wave. We tried to photograph them; but the very poor visibility and the fast motion of the waves resulted only in a blurred print.

Were these steps carved in the wave slopes by high harmonics of the period of the typhoon squalls? These higher harmonics have been registered by sensitive modern microbarographs, and they might have something to do with the quite peculiar scream. ing of the wind, often reported by seamen during the squalls of tropical storms. Strangely enough, this peculiar whistling has never been noticed in the squall line of extratropical storms.

E. GHERZI, S.J.

St. Louis University,

St. Louis 3, Missouri. 